\title{
Hippotherapy in Adult Patients with Chronic Brain Disorders: A Pilot Study
}

\author{
Hyuk Sunwoo, M.D., Won Hyuk Chang, M.D., Ph.D., Jeong-Yi Kwon, M.D., Ph.D., \\ Tae-Won Kim, M.D., Ji-Young Lee, PT, Yun-Hee Kim, M.D., Ph.D. \\ Department of Physical and Rehabilitation Medicine, Samsung Medical Center, \\ Sungkyunkwan University School of Medicine, Seoul 135-710, Korea
}

Objective To investigate the effects of hippotherapy for adult patients with brain disorders.

Method Eight chronic brain disorder patients (7 males, mean age 42.4 \pm 16.6 years) were recruited. The mean duration from injury was $7.9 \pm 7.7$ years. The diagnoses were stroke $(n=5)$, traumatic brain disorder $(n=2)$, and cerebral palsy $(n=1)$. Hippotherapy sessions were conducted twice a week for eight consecutive weeks in an indoor riding arena. Each hippotherapy session lasted 30 minutes. All participants were evaluated by the Berg balance scale, Tinetti Performance-Oriented Mobility Assessment, 10 Meter Walking Test, Functional Ambulatory Category, Korean Beck Depression Inventory, and Hamilton Depression Rating Scale. We performed baseline assessments twice just before starting hippotherapy. We also assessed the participants immediately after hippotherapy and at eight weeks after hippotherapy.

Results All participants showed no difference in balance, gait function, and emotion between the two baseline assessments before hippotherapy. During the eight-week hippotherapy program, all participants showed neither adverse effects nor any accidents; all had good compliance. After hippotherapy, there were significant improvements in balance and gait speed in comparison with the baseline assessment $(p<0.05)$, and these effects were sustained for two months after hippotherapy. However, there was no significant difference in emotion after hippotherapy.

Conclusion We could observe hippotherapy to be a safe and effective alternative therapy for adult patients with brain disorders in improving balance and gait function. Further future studies are warranted to delineate the benefits of hippotherapy on chronic stroke patients.

Key Words Brain disorder, Hippotherapy, Balance, Gait

Received May 9, 2012; Accepted July 8, 2012

Corresponding author: Won Hyuk Chang

Department of Physical and Rehabilitation Medicine, Samsung Medical Center, Sungkyunkwan University School of Medicine, 50, Ilwon-dong, Gangnam-gu, Seoul 135-710, Korea

Tel: +82-2-3410-6068, Fax: +82-2-3410-2820, E-mail: wh.chang@samsung.com

(c) This is an open-access article distributed under the terms of the Creative Commons Attribution Non-Commercial License (http://creativecommons. org/licenses/by-nc/3.0) which permits unrestricted noncommercial use, distribution, and reproduction in any medium, provided the original work is properly cited.

Copyright @ 2012 by Korean Academy of Rehabilitation Medicine 


\section{INTRODUCTION}

Hippotherapy is a form of therapy that uses the movement of a horse as part of an integrated therapy program thereby providing the rider with postural or strength training opportunities. This therapy engenders integrated sensory stimulation, including vestibular, tactile, visual, and postural senses, as well as motor reaction, and even promoting head and trunk stabilization. ${ }^{1}$ Hippotherapy encompasses not only those activities based on the movement of the horse but also various forms of postural and movement training for the rider that are conducted during therapy sessions. Thus, riders are guided into different riding positions on the horse, from the normal riding position of sitting forward and straddling the horse's back to those of sitting backward and straddling the horse, or sitting with both legs on one side. Sometimes, they are directed to take crawling, keeling, or standing positions depending on the goal of treatment. ${ }^{1}$

The theoretical background of hippotherapy is motor learning and control; namely, an intensive performance of experience of learning reaction to the rhythmic movement of the horse. ${ }^{2,3}$ The horse's walk, in particular, consists of accurate, smooth, rhythmic, and repetitive movements similar to human gait; hence, it repeatedly provides experiences similar to human walking to the riders with declined gait function. ${ }^{4,5}$ As the horse takes 55 walking steps per minute on average, which is a moderate gait speed, riders may perform 3,000 to 5,000 times of trunk balance exercise while riding the horse for 30 to 45 minutes. ${ }^{1}$ Accordingly, at each step of the horse, its right and left hind legs enable the rider's pelvis to move somewhat vertically and horizontally along with the three axes of rotational movement.

To date, studies on hippotherapy have been focused mainly on children with cerebral palsy. It has been reported that the therapy is effective in improving balance ability, symmetry of the trunk and pelvic muscles, and gross motor. ${ }^{3,5-9}$ Some recent studies have focused on adults, reporting that it reduces spasticity and improves balance ability in patients with spinal cord injuries ${ }^{10,11}$ and those with multiple sclerosis. ${ }^{12,13}$ However, studies on hippotherapy for adult patients with brain disorders have been lacking. Thus, we aim to examine the effectiveness of hippotherapy in improving the motor skills of adult brain disorder patients.

\section{MATERIALS AND METHODS}

\section{Subjects}

Among adult outpatients with chronic brain disorders, whose time after onset was at least six months, and who visited the Department of Physical and Rehabilitation Medicine, Samsung Medical Center between May 2010 and August 2011, we recruited those who had trouble with balance and gait speed although being capable of independent gait at the level of three points or higher on the Functional Ambulatory Category (FAC). ${ }^{14}$ Meanwhile, those with declined cognitive function, who might have the disability to perform the tasks as instructed during hippotherapy sessions, were excluded based on clinical judgments. Moreover, those with orthopedic problems (severe osteoporosis, lordosis or kyphosis, pathologic fracture, scoliosis with a curvature of 30 degrees or more, spondylolisthesis, or spinal instability) or seizure disorders that might cause safety-related problems during therapy sessions were excluded through a systemic review and a radiological examination prior to treatment. Those who verbally consented to the purpose of this study after being provided with a full explanation about the risk factors of hippotherapy, such as a fall and a fracture, through an interview were finally selected. Lastly, patients who weighed $75 \mathrm{~kg}$ or more were excluded in consideration of the limit of the load carrying capacity of the horse.

The final subjects were eight in all, and their average age was 42.4 years old. Their diagnoses and general characteristics are shown in Table 1. All the participants had been doing balance and gait training through an outpatient physical treatment two or three times a week before participating in this study. They continued rehabilitation treatment at the same level of intensity during this experiment.

\section{Methods}

Hippotherapy: Hippotherapy sessions were conducted in an indoor riding arena, $18 \times 27 \mathrm{~m}$, with soft soil on the ground, and a Western horse that was tamed properly and safely was used. All the participants wore protective headgear. Then, one leader held the reins and led the horse in front, while the two side walkers held each leg of the patient sitting on the saddle from each side in order to prevent a fall from the horse, facilitating the patient's movements performed on the horse. Furthermore, while 
Table 1. General Characteristics of Participants

\begin{tabular}{ccclccc}
\hline & Sex & Age & \multicolumn{1}{c}{ Diagnosis } & $\begin{array}{c}\text { Height } \\
(\mathbf{c m})\end{array}$ & $\begin{array}{c}\text { Weight } \\
(\mathbf{k g})\end{array}$ & $\begin{array}{c}\text { Duration } \\
\text { (yrs) }\end{array}$ \\
\hline Case 1 & M & 25 & Cerebral palsy, spastic diplegia & 165 & 56 & 25.0 \\
Case 2 & M & 36 & Traumatic brain injury & 170 & 73 & 8.3 \\
Case 3 & M & 26 & Bilateral pons ICH & 174 & 68 & 2.2 \\
\hline Case 4 & M & 53 & Lt. thalamic ICH & 170 & 74 & 10.8 \\
Case 5 & M & 70 & Rt. paramedian pons infarct & 167 & 60 & 2.6 \\
\hline Case 6 & F & 53 & Lt. BG ICH & 160 & 47 & 3.9 \\
\hline Case 7 & M & 50 & Lt. medulla infarction & 169 & 66 & 1.4 \\
\hline Case 8 & M & 26 & Traumatic brain injury & 170 & 64 & 9.3 \\
\hline Mean \pm SD & M: 7, F: 1 & $42.4 \pm 16.6$ & & $168.1 \pm 4.2$ & $63.5 \pm 9.0$ & $7.9 \pm 7.8$ \\
\hline
\end{tabular}

ICH: Intracerebral hemorrhage, Lt: Left, Rt: Right

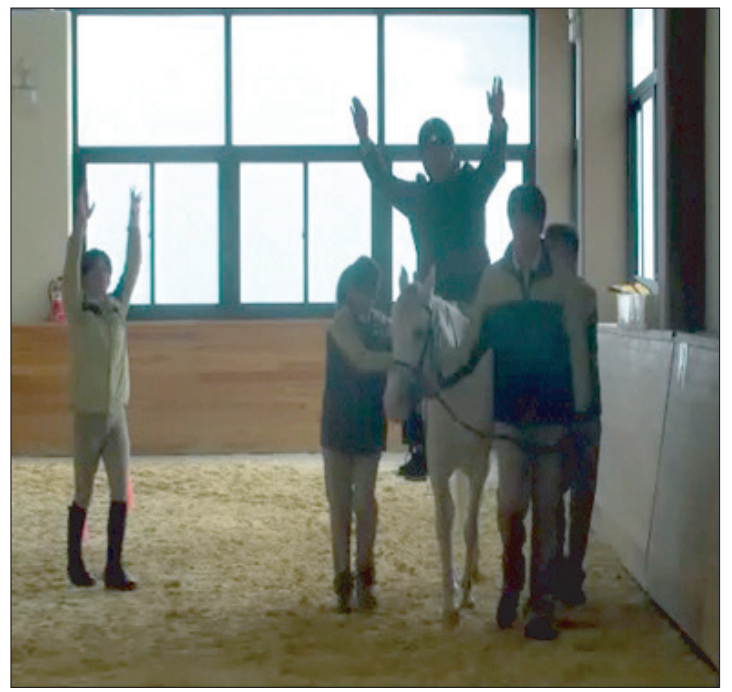

Fig. 1. Hippotherapy.

each subject was riding, a physical therapist, trained by the American Hippotherapy Association, was present in order to direct him or her to perform various motions for improving sensory-motor and cognitive-motor abilities (Fig. 1).

All the subjects participated in 16 hippotherapy sessions twice a week for eight consecutive weeks, with each session lasting 30 minutes.

Functional assessments: Functional assessments were conducted in terms of four areas of balance ability, gait function, emotion, and performance of activities of daily living (ADL). To assess the subjects' balance ability, the Korean Berg Balance Scale (K-BBS $)^{15}$ and the Tinetti Performance-Oriented Mobility Assessment (POMA) ${ }^{16}$ were used. Their gait function was measured by 10 Meter Walking Test $(10 \mathrm{mWT})^{17}$ and the FAC. ${ }^{14}$ Moreover, their emotion was evaluated based on the Korean Beck Depression inventory (K-BDI) ${ }^{18}$ and the Hamilton Depression Rating Scale (Ham-D). ${ }^{19}$ In addition, their ADL performance was assessed using the modified Barthel index (K-MBI). ${ }^{20}$

Considering that all of the subjects continued their rehabilitation treatment, a set of assessments were conducted before the hippotherapy at the same interval as the duration of hippotherapy in order to compare the changes in their conditions resulting from treatments other than hippotherapy and those resulting from hippotherapy. To determine the continuance of the effects of the therapy, another set of assessments were carried out at the same interval as the duration of hippotherapy. As such, assessments were prepared four times in total; namely Pre-Therapy 1 at eight weeks before the therapy, Pre-Therapy 2 immediately before the therapy, PostTherapy 1 immediately after the therapy, and Post-Therapy 2 at eight weeks after the therapy.

Statistical analysis: This is a pilot study and thus, we adopted the one-group pretest- posttest design. For statistical analysis, SPSS for Windows, version 19.0 was used. The Wilcoxon signed-rank test was used to analyze the changes at each assessment, differences between the two times of assessment before the hippotherapy, and those between pre-therapy and post-therapy assessments. A p-value less than 0.05 was considered statistically significant. 


\section{RESULTS}

All eight subjects safely completed the 16 hippotherapy sessions for eight weeks. No safety accident, such as a fall from the horse, took place, and no subject showed musculoskeletal pain or adverse effects that required medical care after hippotherapy.

\section{Balance ability}

The participants showed no significant differences in the scores for the K-BBS and the POMA between PreTherapy 1 and Pre-Therapy 2 , while they revealed significant positive changes between Pre-Therapy 2 and PostTherapy $1(\mathrm{p}<0.05)$. There were no significant differences between Post-Therapy 1 and Post-Therapy 2 (Table 2). In terms of the scores for the K-BBS, the rate of change between the two pre-therapy assessments and that between the pre-therapy and post-therapy assessments were $1.7 \pm 6.9 \%$ and $9.3 \pm 8.9 \%$, respectively, indicating that the change between before and after hippotherapy was significantly higher $(\mathrm{p}<0.05)$. Moreover, when it comes to the scores for the POMA, the rate of change between the two pre-therapy assessments and that between the pretherapy and post-therapy assessments were $3.8 \pm 7.6 \%$ and $12.9 \pm 11.3 \%$, respectively, suggesting that the change between before and after hippotherapy was significantly higher $(\mathrm{p}<0.05)$.

\section{Gait function}

In terms of the $10 \mathrm{mWT}$, there were no significant differences between Pre-Therapy 1 and Pre-Therapy 2, while there were significant improvements in gait speed between Pre-Therapy 2 and Post-Therapy $1(\mathrm{p}<0.05)$. The subjects did not reveal any significant differences between Post-Therapy 1 and Post-Therapy 2 (Table 2). The rate of change between the two pre-therapy assessments and that between the pre-therapy and post-therapy assessments were $3.8 \pm 14.2 \%$ and $-16.3 \pm 18.2 \%$, respectively, suggesting that the rate of change between before and after hippotherapy was significantly higher $(\mathrm{p}<0.05)$.

The subjects did not show any significant difference in the FAC results at each time of assessment (Table 2).

\section{Emotion}

The subjects did not show any significant difference in emotion at each time of assessment in terms of the K-BID and the Ham-D (Table 2).

\section{ADL performance}

The subjects did not show any significant difference in ADL performance at each time of assessment in terms of the K-MBI (Table 2).

\section{DISCUSSION}

In this study, although we did not observe any significant changes in gait ability for eight weeks before the therapy, which was measured based on the K-BBS and the POMA, we saw improvements right after the therapy and the lasting effects at the assessment at eight weeks after therapy. The results regarding gait speed, measured using the $10 \mathrm{mWT}$, were similar to those regarding balance ability. Such results suggest that hippotherapy is effective in improving balance ability and gait speed of

Table 2. Functional Assessments before and after Hippotherapy

\begin{tabular}{lcccc}
\hline & Pre-therapy 1 & Pre-therapy 2 & Post-therapy 1 & Post-therapy 2 \\
\hline K-BBS & $38.9 \pm 13.1$ & $38.9 \pm 11.9$ & $42.0 \pm 12.0^{*}$ & $42.8 \pm 12.1$ \\
POMA & $19.8 \pm 5.7$ & $20.1 \pm 5.3$ & $22.4 \pm 5.5^{*}$ & $22.3 \pm 5.5$ \\
10 mWT (s) & $56.9 \pm 50.1$ & $61.1 \pm 56.0$ & $47.8 \pm 44.0^{*}$ & $49.1 \pm 46.6$ \\
FAC & $4.3 \pm 0.7$ & $4.3 \pm 0.7$ & $4.3 \pm 0.7$ & $4.3 \pm 0.7$ \\
K-BDI & $9.5 \pm 9.8$ & $7.8 \pm 8.1$ & $7.0 \pm 8.9$ & $7.9 \pm 11.3$ \\
Ham-D & $4.4 \pm 4.1$ & $3.9 \pm 3.6$ & $3.1 \pm 3.9$ & $3.6 \pm 4.2$ \\
K-MBI & $83.1 \pm 7.6$ & $83.1 \pm 8.1$ & $84.1 \pm 8.5$ & $84.8 \pm 8.3$ \\
\hline
\end{tabular}

K-BBS: Korean Berg Balance Scale, POMA: Tinetti Performance-Oriented Mobility Assessment, 10 mWT: 10 Meter Walking Test, FAC: Functional ambulatory category, K-BDI: Korean Beck Depression inventory, HAM-D: Hamilton Depression Rating Scale, K-MBI: Korean Modified Barthel Index (K-MBI)

${ }^{*} \mathrm{p}<0.05$ between Pre-therapy 2 and Post-therapy 1 
adult patients with chronic brain disorders and the effects last at least eight weeks.

Hippotherapy specifically means a type of therapy in which a team of therapists with official hippotherapyrelated licenses perform treatment by applying various methods while the rider is riding on a slowly walking horse. This is distinguished from the Horseback Riding Therapy (HBRT) in which therapists are present to play a subordinate role, such as helping to maintain the rider's safety. ${ }^{21}$ Hippotherapy has been studied by focusing largely on child patients thus far. It is known that the exercise physiological effects of hippotherapy involve enabling the child patient to experience walking similar to the average human gait through his or her trunk because the movement felt on the saddle when the horse is slowly walking is similar to the pelvic movement that healthy people produce during gait, thereby strengthening the trunk muscles and improving balance ability as the trunk responds to the movement. ${ }^{21,22}$ In this study as well, we observed that chronic brain disorder patients' balance ability improved after the eight-week hippotherapy program, and moreover, the effects lasted longer than eight weeks. These results indicate that hippotherapy is effective for adult patients with brain disorders as well as for child patients. The subjects' gait speed also improved after therapy. The factors related to brain disorder patients' gait ability include balance ability, motor skill, sensory function, and cognitive function, and among these factors, balance ability is known to have the closest association with gait ability. ${ }^{23}$ Moreover, for brain disorder patients, it has been reported that trunk balance during gait plays a major role in the stability and effectiveness of gait. ${ }^{24}$ In this regard, we can conclude that the improvements in gait speed observed in this study after hippotherapy resulted from the enhanced balance ability, particularly, trunk balance ability. Nevertheless, since we did not assess the other factors related to gait ability, such as motor skill, sensory function, and cognitive function, this study lacks convincing evidence. Therefore, assessments of the three factors before and after hippotherapy should be conducted in future relevant studies.

In this study, there were no significant differences observed in gait ability, which was measured based on the FAC, and performance of ADL at each time of assessment. This is presumably because of the small sample size of having only eight subjects. However, this may suggest that the therapeutic effects of hippotherapy are not significant enough to surpass those of conventional rehabilitation treatments. Hippotherapy has been reported to be effective in promoting children's self-confidence and emotion, and such effects are considered to result from activities along with nature, including a horse. ${ }^{3}$ We also assessed the subjects' emotion by using the K-BDI and the Ham-D; however, there were no significant changes observed between before and after hippotherapy. The results presumably stem from mild depressive tendencies that all the subjects had, hence, they are not decisive enough to lead to a conclusion that hippotherapy does not have any emotional effects in adult patients with chronic brain disorders. Further studies are necessary regarding this matter.

As a pilot study for a large-scale therapy-control group study in the future, this study has several limitations. To begin with, the possibility that the lack of diversity of the sample, due to the small number of subjects, might have influenced the results should not be neglected. In addition, the total amount of other treatments was not controlled because hippotherapy was considered as an alternative or adjuvant form of therapy. Another limitation is that participants had a variety of diseases despite the small sample size, such as stroke, traumatic brain injury, and cerebral palsy. Nonetheless, all of the participants safely completed the eight-week hippotherapy program without any particular adverse effects, and their balance ability and gait speed, which did not reveal any improvement at the pre-therapy assessments conducted at the same interval as the duration of the therapy, were enhanced after the therapy. Such results suggest that hippotherapy can be considered as a complementary treatment method added to the conventional rehabilitation treatments with the aim of improving chronic brain disorder patients' balance ability and gait speed.

\section{CONCLUSION}

In this study, we ascertained that hippotherapy, which is a form of therapy that helps adult patients with chronic brain disorders to engage in balance training and improve gait function, has the potential of being a complementary treatment that can be provided with the use of traditional exercise therapy. We also see the necessity of future comprehensive studies on the effects of hippotherapy through a therapy-control group analysis involving a large number of patients. 


\section{REFERENCES}

1. Strauss I. Hippotherapy: neurophysiological therapy on the horse, Ontario: Ontario Therapeutic Riding Assoication, 1995, 11-25

2. Casady RL, Nichols-Larsen DS. The effect of hippotherapy on ten children with cerebral palsy. Pediatr Phys Ther 2004; 16: 165-172

3. Sterba JA, Rogers BT, France AP, Vokes DA. Horseback riding in children with cerebral palsy: effect on gross motor function. Dev Med Child Neurol 2002; 44: 301308

4. McGee MC, Reese NB. Immediate effects of a hippotherapy session on gait parameters in children with spastic cerebral palsy. Pediatr Phys Ther 2009; 21: 212218

5. Bertoti DB. Effect of therapeutic horseback riding on posture in children with cerebral palsy. Phys Ther 1988; 68: 1505-1512

6. McGibbon NH, Andrade CK, Widener G, Cintas HL. Effect of an equine-movement therapy program on gait, energy expenditure, and motor function in children with spastic cerebral palsy: a pilot study. Dev Med Child Neurol 1998; 40: 754-762

7. McGibbon NH, Benda W, Duncan BR, SilkwoodSherer D. Immediate and long-term effects of hippotherapy on symmetry of adductor muscle activity and functional ability in children with spastic cerebral palsy. Arch Phys Med Rehabil 2009; 90: 966-974

8. Benda W, McGibbon NH, Grant KL. Improvements in muscle symmetry in children with cerebral palsy after equine-assisted therapy (hippotherapy). J Altern Complement Med 2003; 9: 817-825

9. Shurtleff TL, Standeven JW, Engsberg JR. Changes in dynamic trunk/head stability and functional reach after hippotherapy. Arch Phys Med Rehabil 2009; 90: 1185-1195

10. Lechner HE, Kakebeeke TH, Hegemann D, Baumberger $\mathrm{M}$. The effect of hippotherapy on spasticity and on mental well-being of persons with spinal cord injury. Arch Phys Med Rehabil 2007; 88: 1241-1248

11. Lechner HE, Feldhaus S, Gudmundsen L, Hegemann D, Michel D, Zach GA, Knecht H. The short-term effect of hippotherapy on spasticity in patients with spinal cord injury. Spinal cord 2003; 41: 502-505

12. Silkwood-Sherer D, Warmbier H. Effects of hippotherapy on postural stability, in persons with multiple sclerosis: a pilot study. J Neurol Phys Ther 2007; 31: 77-84

13. Hammer A, Nilsagard Y, Forsberg A, Pepa H, Skargren E, Oberg B. Evaluation of therapeutic riding (Sweden)/ hippotherapy (United States). A single-subject experimental design study replicated in eleven patients with multiple sclerosis. Physiother Theory Pract 2005; 21: 51-77

14. Holden MK, Gill KM, Magliozzi MR, Nathan J, PiehlBaker L. Clinical gait assessment in the neurologically impaired. Reliability and meaningfulness. Phys Ther 1984; 64: 35-40

15. Jung HY, Park JH, Shim JJ, Kim MJ, Hwang MR, Kim $\mathrm{SH}$. Reliability test of Korean version of Berg balance scale. J Korean Acad Rehab Med 2006; 30: 611-618

16. Cipriany-Dacko LM, Innerst D, Johannsen J, Rude V. Interrater reliability of the Tinetti Balance Scores in novice and experienced physical therapy clinicians. Arch Phys Med Rehabil 1997; 78: 1160-1164

17. Graham JE, Ostir GV, Fisher SR, Ottenbacher KJ. Assessing walking speed in clinical research: a systematic review. J Eval Clin Pract 2008; 14: 552-562

18. Lee MG, Lee YH, Park SH, Sohn CH, Jung YJ, Hong SG, Lee BG, Jang P, Yun A. A standardization study of beck depression inventory (I): Korean version (K-BDI): reliability land factor analysis. Kor J Psychopathol 1995; 4: 77-95

19. Hamilton M. A rating scale for depression. J Neurol Neurosurg Psychiatry 1960; 23: 56-62

20. Wade DT, Skilbeck CE, Hewer RL. Predicting Barthel ADL score at 6 months after an acute stroke. Arch Phys Med Rehabil 1983; 64: 24-28

21. Sterba JA. Does horseback riding therapy or therapistdirected hippotherapy rehabilitate children with cerebral palsy? Dev Med Child Neurol 2007; 49: 68-73

22. Snider L, Korner-Bitensky N, Kammann C, Warner S, Saleh M. Horseback riding as therapy for children with cerebral palsy: is there evidence of its effectiveness? Phys Occup Ther Pediatr 2007; 27: 5-23

23. de Oliveira CB, de Medeiros IR, Frota NA, Greters ME, Conforto AB. Balance control in hemiparetic stroke patients: main tools for evaluation. J Rehabil Res Dev 2008; 45: 1215-1226

24. Richards CL, Malouin F, Wood-Dauphinee S, Williams JI, Bouchard JP, Brunet D. Task-specific physical therapy for optimization of gait recovery in acute stroke patients. Arch Phys Med Rehabil 1993; 74: 612-620 